The Geneva Papers on Risk and Insurance, 22 (No. 83, April 1997) 187-189

\title{
Comments on Howard Kunreuther's Article
}

\author{
by Göran Skogh*
}

1. An underpinning in Professor Kunreuther's paper is that the insurance industry can improve by an extended use of scientific methods. Much can be learned from technical, natural, and computer science, as well as from financial economics. This is especially true for catastrophic risks. Risk assessment of industrial hazards, climatic changes, and new interpretations of liability law cannot successfully be based solely on traditional actuarial science that mainly focuses on historical data and general experiences within the industry.

I generally agree with Professor Kunreuther's standpoint. Huge losses have seriously weakened the financial strength and prestige of the insurance industry. Future insurance is an advanced service industry that requires large investments in human capital, new technologies, and contractual forms. Scientific work needs to be done, both within the industry and in terms of independent research. Long-term work based on scientific methodology is the most promising way to avoid the kind of large mistakes experienced recently in various branches of the industry.

2. Below, I will add to Professor Kunreuther's arguments with some comments on the insurability issue. In my view, the debate on the limits of the insurance business appears misleading and conservative in favour of the old and mature lines of business.

3. In the standard model of "perfect" insurance it is assumed (a) that the risk is given by nature and, thus, not influenced by moral hazard or adverse selection, and (b) that both the insurer and the insured know (or subjectively estimate) the same probability and loss distribution. Under these circumstances it is easy to show that insurance may be mutually beneficial for the risk-adverse policy-holder and the risk-neutral insurer. The model is a good illustration of the benefits of insurance but it is misleading when used as a framework in the discussion on the limits of the insurance business. According to the model, the main obstacles to insurance are (i) uncertainty, which renders estimates on accident risks impossible, (ii) moral hazard, (iii) adverse selection, and (iv) limited capacity to diversify risks. These phenomena certainly cause problems, but the insurance industry may be able to solve them.

* Associate Professor, Department of Economics and the International Institute for Industrial Environmental Economics, Lund University, Sweden 
Note that under perfect conditions insurance can be traded as a lottery, or as an option on the financial market without transaction costs. In other words, insurance will be perfect without an insurance industry. We reach, thus, the somewhat paradoxical conclusion that under perfect insurance there is no need for an insurance industry; and under the uninsurability conditions above the industry is unable to insure.

A basic question that needs to be answered is, therefore, how to legitimize the insurance industry. An answer can be found in the economics of financial intermediation first applied to banks (Benson and Smith, 1976, and Leland and Pyle, 1977). The basic issues in this early literature were: Why do lenders and borrowers not trade directly via credit markets? Why do they use costly intermediaries like banks? The answer given is based on a presumption of asymmetric information, that is, the borrower has some hidden information about his ability and intention to pay back. Because the credit risk is not known publicly, there is a demand for firms specialised in information on borrowers. The reason why such firms do not act as consultants to avoiding the credit risks is two-fold. First, the information may be "transaction specific" (Williamson, 1979) and, hence, not easily traded. Second, the information is a public good once it is spread. Therefore, a firm selling information may not be able to appropriate enough of the value of the information to cover the costs of information acquisition.

This explains why intermediaries exist who accept credit risks - the profit will depend directly on the special information available to the creditor. That is one reason why we observe banks specialised in households, agriculture farming, shipping, and other branches of industry. The same theory can be applied to insurance (Skogh, 1991). The insurer is, as is the bank, a risk carrier. The profit depends directly on information about the risk, the terms of the contract, the claims, and the portfolio of assets and liabilities. That explains why we observe the same branches of insurance around the world: property, liability, traffic, health, pension, and life. The reason appears to be the comparative advantage in specialisation in information regarding the different risks.

This institutional theory gives a rationale for the insurance industry - the insurance firm is there because it has been able to solve problems of limited information about risks, moral hazard, adverse selection, and limited diversification capacity. Consequently, the success of the insurance industry depends on the organisational and informational advantages accrued. Advanced knowledge based on scientific methods is, thus, of crucial importance.

4. The challenge of the industry ought to be to solve new problems that arise. It is often said that new risks cannot be insured because of lack of experience and historical data. For instance, how should the risk be priced if no one knows whether the probability of a loss is 0.01 or 0.0001 ? This argument is valid when insurance is narrowly defined to be a contract where an agent trades a risk with an insurer at a premium fixed ex ante. However, the industry is also involved in mutual risk-sharing, that is, when two or more agents agree to share losses with each other. Sharing of actual losses may be mutually beneficial in spite of the lack of information about the probability of losses. It is enough that parties in the pool are faced with the same risk and that they trust each other's capability and willingness to fulfil the agreement (Skogh, 1996).

Mutual pools of parties facing similar risks, without accurate information of probabilities of losses, have existed for centuries. Joint ventures are modern examples - a group of risk-averse entrepreneurs facing the same risks may gain by sharing profits and losses, 
although they lack experience in the business. Sharing risks in groups of equals is also, to some extent, used in relation to modern catastrophic hazards, for instance, in atomic pools and in "compensation and indemnity clubs" covering oil pollution. Hence, there are pooling alternatives even when the prerequisites of insurance are not fulfilled, and the industry has a comparative advantage in organising such pools.

5. Recent economic failures in the insurance industry have caused a widely spread pessimism - the attitude is defensive rather than offensive. Frustration and stress may explain the withdrawal from risky affairs and a tendency to stick to the traditional, well-known, and mature lines of business. Nevertheless, in the long run it is impossible to survive on old merits, and it is the new risks that are challenging and potentially profitable. Indeed, new hazards, environmental problems, and reductions of the Welfare State open new, very large fields for the insurance sector. Needless to say, this new business is also risky. However, the industry is there to take calculated risks. The best way to avoid mistakes and, thus, ensure long-term profits is systematic work based on scientific methods within diverse areas, such as economics, statistics, technical and natural sciences, computer science, and law.

\section{REFERENCES}

BENSTON, G. J. and SMITH, C. W., Jr. (1976), "A Transactions Cost Approach to the Theory of Financial Intermediation", The Journal of Finance, Vol. 31, No. 2, pp. 215-231.

LELAND, H. and PYLE, D. (1977), "Informational Asymmetries, Financial Structure, and Financial Intermediation", Journal of Finance, Vol. 32, pp. 371-387.

SKOGH, G. (1991), "Insurance and the Institutional Economics of Financial Intermediation", Geneva Papers on Risk and Insurance, pp. 360-370.

SKOGH, G. (1996), "Uncertainty, Mutual Risk-sharing, and the Evolution of Insurance", International Institute for Industrial Environmental Economics, Memo.

WILLIAMSON, O. E., "Transaction Cost Economics: The Governance of Contractual Relations", Journal of Law and Economics, 22, pp. 13-62. 